\title{
3.8 The Importance of Micro-and Macrocirculation Indices Implementation for the Amelioration of Cardiovascular Risk Classification
}

\author{
Triantafyllou Areti, Dipla Konstantina, Koletsos Nikolaos, Gkaliagkousi Eugenia, Lazaridis Antonios, \\ Zafeiridis Andreas, Douma Stella
}

Aristotle University of Thessaloniki, Greece

\begin{abstract}
Recently, many promising indices of micro- and macrocirculation have been widely used to promptly detect target organ damage before major cardiovascular events occur. More specifically, nailfold capillaroscopy, fundoscopy, near-infrared spectroscopy, ultrasound, laser speckle contrast analysis and central arterial pressure waveform analysis have been used to reveal capillary rarefaction, retinal vessel alterations, reduced brain and muscle oxygenation, endothelial dysfunction and arterial stiffness respectively. Additionally, the cross-talk between macro- and microvascular alterations has been a topic intensively discussed during the last years. Contrary to what someone might expect, i.e. that different microvascular target organ damage will coexist and occur at the same time in different tissues of the human body, in most studies the different types of microangiopathy seem not to synchronize or follow a specific order of appearance but rather to affect the different tissues randomly. On the other hand, arterial stiffening of the large arteries seems consistently to co-exist and correlate with almost all microvascular lesions. Nevertheless, many questions arise: When do the above lesions coexist? In which individuals? In which diseases? What can they predict when identified in apparently healthy people? In the present paper, the results of the study of the above indices, all applied in the same individuals at the same time, will be presented in a variable spectrum of diseases (naïve hypertensives, diabetics, rheumatologic patients, women with gestational diabetes, obese people, as well as healthy controls) to explore not only the interactions between them but mostly their importance for the amelioration of cardiovascular risk classification.
\end{abstract}

\section{REFERENCES}

[1] Anyfanti P, Gkaliagkousi E, Triantafyllou A, Dipla K, Zarifis H, Arseniou P, et al. Noninvasive assessment of myocardial perfusion in different blood pressure phenotypes and its association with arterial stiffness indices. Am J Hypertens 2019;32:557-63.

[2] Triantafyllou A, Anyfanti P, Gkaliagkousi E, Zabulis X, Vamvakis A, Gkolias V, et al. Association of urinary sodium excretion with vascular damage: a local kidney effect, rather than a marker of generalized vascular impairment. Int J Hypertens 2018:7620563.

[3] Dipla K, Triantafyllou A, Koletsos N, Papadopoulos S, Sachpekidis V, Vrabas IS, et al. Impaired muscle oxygenation and elevated exercise blood pressure in hypertensive patients: links with vascular stiffness. Hypertension 2017;70:444-51.

[4] Triantafyllou A, Anyfanti P, Gavriilaki E, Zabulis X, Gkaliagkousi E, Petidis K, et al. Association between retinal vessel caliber and arterial stiffness in a population comprised of normotensive to early-stage hypertensive individuals. Am J Hypertens 2014;27:1472-8.

[5] Triantafyllou A, Anyfanti P, Zabulis X, Gavriilaki E, Karamaounas P, Gkaliagkousi E, et al. Accumulation of microvascular target organ damage in newly diagnosed hypertensive patients. J Am Soc Hypertens 2014;8:542-9.

(c) 2019 Association for Research into Arterial Structure and Physiology. Publishing services by Atlantis Press International B.V. This is an open access article distributed under the CC BY-NC 4.0 license (http://creativecommons.org/licenses/by-nc/4.0/) 